\title{
The impact of education in shaping lives: reflections of young people with disabilities in Ghana
}

Nidhi Singal

Faculty of Education, University of Cambridge

sn241@cam.ac.uk

Edward Mahama Salifu

Associates for Change (AfC), Accra-North, Ghana

comdev9@yahoo.com

Khadijatu Iddrisu

Associates for Change (AfC), Accra-North, Ghana

comdev9@yahoo.com

Leslie Casely-Hayford

Associates for Change (AfC), Accra-North, Ghana

comdev9@yahoo.com

Helen Lundebye

Faculty of Education, University of Cambridge

hlundebye@gmail.com 
There is increasing recognition on the importance of focusing on people with disabilities in international efforts aimed at poverty alleviation. While universal education has been central to these efforts, the specific and additional needs of children with disabilities are often overlooked in policies and programmes. In order to gain a nuanced appreciation of the lives of young people with disabilities in a Ghanaian context, this paper draws on research conducted with young people with disabilities and their significant others in order to understand their educational journeys, employment prospects and perceptions of those around them. In addition to collecting primary data, the latest policy documents related to disability, education and employment are reviewed and statistical analysis undertaken based on the Housing and Population Census 2010. Our research highlights the barriers facing those with disability in accessing quality education. While education was recognised as paramount to leading a better life and participants noted benefits beyond employment such as gaining self-sufficiency and social benefits, unequal educational opportunities underpin some of the reasons for the widening of gaps between those with disabilities and their non-disabled counterparts. Furthermore, while education was seen as important for gaining employment, this was not the case in reality, as young people faced difficulties due to both physical and attitudinal barriers limiting their opportunities for economic and social participation in their communities. The paper concludes by noting that systematic changes in the policy arena are needed to enable youth with disabilities to take their rightful place in mainstream society.

Key Words: disability, education, employment, Ghana, youth, poverty

\section{Introduction}

Disability is increasingly becoming part of the mainstream discourse on global development and poverty alleviation. While the Millennium Development Goals (MDGs) are geared towards improving human conditions of all people by 2015, unfortunately the first design of the MDGs has not addressed issues of disability within targeting frameworks (Groce, 2011). Yet, a growing body of research suggests that these goals are unlikely to be attained unless more inclusive strategies for People with Disabilities (PWDs) are integrated into existing plans (DESA, 2011).

According to the World Health Organisation (WHO) (2011), there are more than 1 billion PWDs in the world, of which approximately $80 \%$ live in low income countries. In developing economies, including Ghana, PWDs are most likely to be poor and their lives are characterized by lack of access to public health, education, and other social services. DFID (2000) notes that PWDs in such contexts are most likely to be classified among the poorest of the poor. However, while general impressions of marginalisation and exclusion are available, 
there is very little evidence of a nuanced understanding of their lives. This paper brings to the forefront issues facing young people with disabilities within a Ghanaian context, as presented in their own narratives, reflecting on their educational journeys and discussing their participation in the labour market and community settings.

We begin with an overview of the Ghanaian context by undertaking an analysis of sections of the most recent Housing and Population Census 2010 and by providing a critical review of the latest policy documents related to disability, education and employment. Drawing on the narratives of the young people, we then present their educational experiences (or lack there-of), and discuss the perceived benefits of education particularly in relation to their present lives. Here we also provide insights gathered from their parents, and their influence on the young person's educational journey. The paper concludes with reflections on how systematic developments in policy and practice are needed to respond to the concerns faced by people with disabilities.

\section{Disability in Ghana: an overview}

Since the last census in 2000, the overall population in Ghana has increased $30.4 \%$. Similar to other countries in the region, Ghana has a large youth population with approximately $67 \%$ of the population aged between 0-29 years. According to the 2010 Census Summary Report, the structure of the country's population is shaped by the effects of high fertility rates and decreasing mortality rates (GSS, 2012), with the peak towards the early years.

According to a recent report by the Ghana Statistical Service (GSS) (2013), findings from the 2010 Population and House Census indicated that $2.99 \%$ of the population was identified as having a disability, which equates to over 700,000 people. In analysing the prevalence of disability amongst the youth population, aged 0-29 years, the percentage of the population identified as having a disability reduces to $2 \%$. However, these figures are a gross underestimation when compared to the WHO (2011) figure of $15 \%$ of the population as having a disability. Prevalence of disability type varies according to age group, as evident in Figure 1.

[Insert Figure 1: Young persons with disability by disability type]

Mont (2007), amongst many others, notes that national and international figures on prevalence of disability tend to be unreliable and not comparable due to variations in definitions, data collection methodologies and the quality of research and reporting. This remains true for Ghana. For example, within the Census data gathering procedure variations in the understanding of disability and how the actual question on the survey form is actually framed is clearly evident. In the 2010 census, disability was defined as 'a serious condition which limits the ability of persons to perform specific tasks/activities due to loss of function of some part of the body as a result of impairment or malformation. Persons with disability are those who are unable to or are restricted in the performance of specific tasks/activities' (GSS, 2013, p. xxvi). However in the census questionnaire itself, there is only one question regarding disability. The question posed draws on self-reporting by asking whether the 
individual has 'any serious disability that limits his/her full participation in life activities (such as mobility, work social life, etc.)?'

Despite these problems in data collection, in recent years there has been an increased visibility of disability within legislative and political discourses, as is evident from the passing of the Ghana Persons with Disability Act in 2006 (Act 715). While this Act was heralded as an important landmark, its implementation has been very sketchy (Botts \& Owusu, 2013).

\section{Education}

According to the Global Monitoring Report (GMR) 2013/14, Ghana is considered far from reaching the universal primary enrolment target of $95 \%$ by 2015 (UNESCO, 2014). The report also notes that the gender gaps in learning have more than doubled and the poorest hardly benefit at all, with the literacy rate between rich and poor being more than 50 percentage points between 2003 and 2009. Nearly 50\% of women with disability in the total population lack any form of schooling compared with $32 \%$ of men with disability. Notably, this ratio is similar amongst the non-disabled population.

In Ghana, education of children with disabilities (CWDs) has always been the responsibility of the government, as noted in the National Education Act of 1961 (Anthony and Kwadade, 2006) which mandated the provision of free and compulsory education for all children. The passage of the Education Amendment Act of 1962 empowered the Ministry of Education (MoE) to establish a Special Education Division to oversee the provision and education of students with disabilities (Adera \& Asimeng-Boahene, 2011). The focus in the 1970-80s was on segregated education which resulted in a significant rise in the number of schools for children with visual, hearing and mental disabilities (Anthony, 2009). Avoke (2001) notes that the 'growth of special education in Ghana has not developed significantly from the original model of educating CWDs that was introduced in the 1960s', (p. 39) which comprised predominantly of specialised residential provision. However, over the past twenty years there have been several key policies that have promoted the rights of CWDs (see Table $1)$.

[Insert Table 1: Policies ensuring rights of CWDs here]

According to the 2010 census data, the total population of students attending primary and junior high school (basic education) is around 5.5 million students, while there is no official number of students with disability in education, our calculations based on data provided by the MoE, estimate that in basic education, around 3-4\% of children are reported to have a disability ${ }^{1}$. Furthermore, Anthony and Kwadade (2006) stress on the need to acknowledge the significantly high numbers of students currently enrolled in basic schools across Ghana who have unidentified learning difficulties.

\footnotetext{
${ }^{1}$ As we could not find any official statistics on the percentage of students with disabilities in the total school population, we calculated this percentage by adding the enrolment numbers of students with special needs in mainstream schools (primary and JHS only) to the total number of students enrolled in special schools (which did not disaggregate by school level) and divided it by the total number enrolled in primary and JHS (which is considered 'basic education').
} 
The Ghana Education Strategic Plan (ESP) for the period 2010-2020 has set one of its eight policy objectives to 'improve access to quality education for people with disability' ( $p$. 14) and has incorporated various strategies for ensuring the mainstreaming of CWDs in society. The ESP sets the target for, 'an inclusive education system (to be) achieved by 2015 , including girls and boys with non-severe SENs integrated into mainstream schools' (p. 7) and will also 'provide special schools or education units or for those severely disabled' (p. 32). It is interesting to note that the ESP never explicitly defines the term 'SEN' other than it that it stands for 'special educational needs' or how the determination will be made between those with 'severe' or 'non-severe' disability.

According to the MoE (2013), since the end of 2011, the Inclusive Education (IE) programme has expanded from 29 districts in seven regions, to 46 districts in all ten regions. Interestingly, while the policy mandate has focused on inclusive education, analysis of available secondary data suggests that the official number of pupils in mainstream basic schools has decreased dramatically from 34,729 in 2006/07 to 16,596 in 2012/2013 (MoE, 2013), see Figure 2.

[Insert Figure 2: Number of students with special educational needs enrolled in mainstream basic education here]

According to the MoE this decrease is due to irregularities in the enrolment numbers of CWDs in mainstream schools which they attribute to inconsistencies with recording. In comparing the Education Sector Performance Report (ESPR) 2009 and the ESPR 2013, it is clear how such problems of consistency in reporting and data can arise. The two reports lack consistent measurement parameters, making it difficult and sometimes even impossible to draw comparisons. Undoubtedly, the absence of accurate and comparable data negatively impacts planning of service provision. This is recognised in the latest ESP, which notes one of the nine strategies for achieving 'Inclusive Education and Special Education objectives' as the need to 'determine the prevalence rates of various disabilities and special education needs' (p. 17), and also address issues related to the 'inadequate classification and categorization scheme that defines disability' (Ghana Education Service (GES), 2005, p. 5).

According to the ESRP 2013, enrolment in special schools on the other hand, has remained relatively consistent, with a slight increase over a seven year period from 5,092 in 2006/07, to 6,180 in 2012/13. While the ESP clearly states the need to review special school provision and sets targets to increase special units in mainstream schools, it recognizes that this is insufficient in meeting the needs of all children. As Botts \& Owusu (2013) note the GES's goal of opening 20 new units a year, is insufficient to accommodate the long waiting list of CWDs who continue to be denied any type of educational provision.

In order to better understand the current situation of PWDs, we analysed sections relating to education and employment in the latest Census 2010 data. In our analysis, we found an unexpected trend in relation to the population classified as without any schooling. Our findings suggests that among the population without any schooling the disparity between PWDs and those without disabilities is greater (9.4\%) for the younger population (10-14 years), than the older population (40-45) which was $0.7 \%$, as shown in Figure 3. While one would have hoped that increased efforts towards educational enrolment would have equally 
benefited children with disabilities, these figures suggest that this has not been the case. However, these disparities also highlight that what Rose (2012) terms as the "low-hanging fruit" impact of international goal setting efforts wherein goal setting often leads to attention being paid to "those easiest to reach, making it possible to show progress most quickly". Consequently, while the number of children who are out of school has decreased but within this trend, the disparity between those with and without disabilities has increased, suggesting that while the latter have benefited from enrolment efforts, it is the former group which has remained unreached.

[Insert Figure 3: Percentage difference without schooling by age group between PWDs and non-disabled population here]

However, interestingly our analysis of the Census data also revealed that, as a percentage, more CWDs are reaching middle school level (JHS) or above, than their nondisabled counterparts ${ }^{2}$ (as shown in Figure 4). This suggests that once CWDs are able to access schooling, they are more likely to stay throughout completion. While the reasons for this are unknown, it may be possible that given that there are less employment opportunities for young PWDs they tend to stay on in school, or it is possible that CWDs (those more likely to be enrolled in special schools) receive more specialized attention and instruction and are therefore less likely to drop out.

[Insert Figure 4: Differences in completion of middle-school or above here]

Nonetheless, CWDs remain a neglected group within education. A UNICEF (2012) report suggests that the primary reason for the marginalisation of CWDs tends to be sociocultural factors such as stigma and also general low expectations about their capacity and potential. Negative social perceptions have been accounted in various studies, such as Baffoe's (2013) research with PWDs, family members and professionals working in areas of service provision highlighted their experiences of blatant discrimination, stigma, and negative labelling. Appiagye-Atua (2006) notes that common religious-cultural beliefs consider disability a curse or punishment of sins committed by the individual, their parents or ancestors, resulting in social excluison. Within the educational setting, Morley et al's (2010) research with PWDs enrolled in higher education noted problems ranging from difficulties in accessing the built environment, to the lack of appropriate learning resources, such as Braille and loop systems, negative attitudes, ignorance and prejudice. Furthermore, despite progressive legislations, such as the addition of a mandatory 'SEN Studies' course to the three-year Basic Education Diploma requirements (MoESS, 2008), several studies from Ghana have shown problems in teacher preparation and their confidence in including CWDs in mainstream settings. This includes teachers' incompetence to adapt instructions (Kuyuni \& Abosi, 2011), concerns regarding lack of preparation and inadequate resources (Nketsia \& Saloviita, 2013) and teaching practices which are too prescriptive, inflexible and mechanistic (Agbenyega \& Deku, 2011).

\footnotetext{
${ }^{2}$ This includes both mainstream or special schools as the definition of a school was 'an institution where a person receives at least four hours of education in which the emphasis was not on acquisition of vocational skills or training for trade' (GSS, 2013, p. xxv).
} 


\section{Employment}

Ghana has realized an average annual economic growth rate of 6.8\% during 2001-2012 (ILO, 2014). Data from the 2010 census indicate that unemployment rate more than halved from 2000 to 2010 from $10.4 \%$ to $4.2 \%$, yet youth are about 3.5 times more likely to be unemployed than adults (ISSER, 2010). Youth unemployment rates have risen from $16.4 \%$ in 2000 to $29 \%$ in 2009.

According to the 2010 census, PWDs had lower rates of employment and constituted a larger percentage of those considered 'not economically active', defined as 'persons who did not work and were not seeking for work, this included homemakers, students, retired persons, the disabled and persons who were unable to work due to their age or ill-health' ( $p$. XXv).

Analysis of the census data suggests that PWDs people were more likely to be employed in rural areas than in urban areas, although this was also true for people without disability. Men were more likely to be employed compared to women regardless of disability or location and women were more likely to be 'economically not active' compared to men regardless of disability or location (see Table 2 for full details).

[Insert Table 2: Economic status of individuals with and without disability by gender and location near here]

In reviewing the employment crisis and challenges ahead, the National Employment Policy (2012-2016) notes the following, 'high unemployment and under-employment rates among vulnerable groups including the youth, women and persons with disability, and challenges for mainstreaming the vulnerable and excluded to make them productive' (p. xx). The Policy seeks to fully achieve mainstreaming of PWDs into the socio-economic development process of the country by promising that 'skills development and entrepreneurship programmes will be expanded to enhance the capacity and productivity of persons with disability and provide increased access to labour market' (p. 46). Throughout this policy document, education is regarded as a key to fulfilling the stated goals. In addition, the Act provides special provisions for the employment of PWDs such as tax rebates, 'special incentives' to both employees with disabilities and potential employers, training and tools/materials for PWDs.

Despite increased policy efforts, the rates of unemployment for PWDs remain very high. The National Disability Policy Document (MoESW, 2000) noted the four most common misconceptions in relation to the employment of PWDs: they are perceived as someone else's responsibility; require constant supervision at the work place; are best served in isolated, self-contained settings, and are seen as generally incompetent. Argyema \& Delle (2013) research into attitudes towards employees with disability concluded that while there was no significant difference in attitudes towards employees with disabilities in the private and public sector, few demographic factors did have an impact. They found that employers with higher levels of education, as well as older employers were found to demonstrate significantly more favourable attitudes towards employees with disabilities. Furthermore, they noted that most Ghanaians tend to 'admire disable people who engage in productive 
activities and view those who resort to begging as a source of work as lazy and indeed 'disabled' (p. 58).

Given the strong focus on education and employment within current Ghanaian policy it is interesting to examine how young people with disabilities, who have been through the education system, and exited into the world of employment, understand the impact and role of education in their current lives. While contrasting their narratives and experiences with those young people who for various reasons were unable to attend schooling. The next section provides an overview of the research project which formed the basis for gathering this data.

\section{Overview of the research project}

This research project was undertaken over a one year period in four communities, two each in rural and urban settings in Northern Ghana. We conducted semi-structured interviews with 23 young people with disabilities between the ages of 15-35 years, and also interviewed their significant others (SO), which in all, except one, were parents. Observations were conducted at the household level but also in the community for extended periods. Additionally, in order to get a deeper understanding of the communities, interviews were conducted with four key stakeholders, namely village elders, in each of these settings. Interviews were also conducted with four heads of schools in/near each of the communities. The urban community was the district capital of Savelugu and the rural communities were located within one hour of the district capital. The urban location of the study had a reasonable basic infrastructure, such as a small bank, a Senior High School (SHS), two private basic schools and several basic public schools. In contrast, the schooling provision in the rural settings was more limited, with just one basic primary school (class 1 to 6) and a JHS (ages 12-14), and no SHS (ages 15-17). Majority of people in both the rural and urban sites were mainly subsistence farmers. All the young people came from households where the parents either had no schooling or very limited years of schooling. Family sizes were considerably large (six to over ten people), as is the norm in these communities.

All the interviewers were collected by local researchers who were trained in both qualitative techniques of interviewing and had undergone training in disability research (Singal, 2010). In all cases, interviews were conducted by two people with one leading the interview and the other making notes. In addition to this, all interviews were audio recorded after the necessary permission had been obtained. In keeping with the community norms, we negotiated access and consent for participation at different levels; local administrative officers, community elders, heads of household and the young person. Table 3 provides an overview of our youth sample. All the interviews were translated and transcribed into English by the research team with appropriate member checks at various points. All the translated data was uploaded into the Atlas-ti software to enable efficient data management and also enhance reliability of the coding process. The interview data were coded using the three-step coding proposed by Neuman (2000). To begin with, 'open coding' (p.421) was carried out, which primarily involved giving descriptive codes, and a low level of abstraction to help flag themes from the data. However, as the analysis process continued, the codes became more analytical in nature. This 'second pass' through the data involved the organisation of ideas or themes in a coherent manner. The final step was that of 'selective coding', which involved 
scanning the data and previous codes to organise the overall analysis around several core generalizations or ideas.

The semi-structured interviews conducted with the young people covered the following themes: schooling history, classroom engagement and experiences; perceptions of how education was playing a role in their lives in terms of establishing social networks, seeking employment, knowledge of rights and other opportunities in the community and their own aspirations and notions of self. The framework for the interviews which we used was based on the educational outcomes model framed by Singal (2009) which draws on the quality of life (QOL) approach and notions of lifelong learning. In presenting our findings our aim is to forefront voices of the young people by providing quotes (which have been translated from the local language) and we also use certain identifiers such as the type of impairment the young person has, their level of schooling and their location (urban or rural). There are primarily two reasons for this decision: to enhance the transparency of our findings and also to highlight significant differences, on some dimensions, between the various impairment types and locality.

[Insert Table 3: Youth Participant Sample here]

\section{Findings}

\section{Schooling: access and participation}

Our research sample was very diverse in terms of their level of schooling completed and the kind of employment opportunities they were engaged in. While diversity across these characteristics is not surprising, some broad trends are evident, for example, across all three impairment types, the women in our sample group had the lowest levels of schooling. This could be due to the additional barriers faced by young women with disabilities in accessing education and also a reflection of broader trends, as noted earlier in the paper. Rural and urban differences were also evident in some cases, for example none of the young people with visual impairment living in the rural setting had attended school. In contrast, two young men with visual impairment living in the urban area had completed SHS and beyond. These differences could be attributed to the lack of schools or the large distance to schools, as we shall discuss later. Across the board, amongst the three impairment groups, young people who had hearing impairment were the ones with lowest levels of schooling.

In analysing the educational journeys of those who had been to school, it was clear that those with hearing impairments had exclusively attended special schools, while those with visual impairments had attended both mainstream and special schools, undertaking shifts at various points. In contrast, those with physical impairments were more likely to transfer to vocational settings. Nonetheless, what is significant is that across our sample, the type of school that these young people attended was not a matter of choice, rather it was the result of various push and pull factors working within mainstream schools and the availability (or unavailability) of special schools.

Nonetheless, going to school had been an important aspect, and in some cases a substantial part, in the lives of some of our research participants. Therefore not surprisingly the data we gathered on factors which had acted as barriers or facilitators to their participation in 
schooling were insightful and rich. Broadly, across the participants the main factor which emerged in influencing their schooling decisions was the role of their family. For some young people, family impinged on their participation in school, while in others it was pivotal in giving them the confidence and support to access and continue with their education.

I fought for my own right to attend school. I got enrolled in a government school not too far away from my house without the consent of my father. For some time, I used to hide and attend school until my father gave up his stubborn opposition (Sabir/M/PI/grade12/urban) ${ }^{3}$.

In three cases, the family had been the main facilitator in encouraging the young person to attend and also progress through school. Shafiq's mother felt that it was better that her son attended school because she feared that if he stayed at home he might be bullied by the neighbours. The school in this case acted as a safe haven and was a contrast to the perceptions held by Thema's grandmother who was always worried about her grandchild with a physical impairment and refused to send her to school as she feared that she might be bullied at school. In the case of Esther, like few others, family friends and extended networks provided parents with encouragement and advice to enrol their child in school. Parental decisions regarding their children enrolments were influenced not only by the value they placed in education but were also mitigated by other factors.

A significant barrier to accessing schooling identified by all participants was the issue of cost. Although primary and middle school was made free and compulsory in 1961, many participants lamented on the associated costs of schooling, and particularly in relation to the costs incurred in special schools.

I used to like school a lot, thinking one day I will be a nurse or be employed in government sector. It was due to financial problems that I could not continue with school (Joyce/F/PI/grade8/rural).

Addae (M/PI\&HI/grade7/rural) said that he had heard of a special school for the deaf and managed to secure transfer but his parents were unable to pay fee and he had to return to the non-specialist provision to continue his education. Sono, reflected similarly:

We don't have money to go to school. When you are looking for a school and they give you admission, it amazes me; it seems the parents of a majority of disabled are poor (M/VI/grade12/urban)

This issue of cost which was noted by participants is interesting given that while education is free, there are hidden costs even in mainstream settings. Hashim's (2005) research on education and migration in Northern Ghana describes how the likelihood of children's enrolment was based around a complex mix of factors which included the education level of their parents, particularly mothers, and parental ability to pay indirect and direct costs of schooling, largely determined by the types of livelihoods the households were pursuing. Reflections of these are also evident in our study. In the case of families sending their child with disabilities to a special school, the parents noted, these were not completely free, even when they were run by charities.

\footnotetext{
${ }^{3}$ Denotes: Name (if not previously used)/gender/impairment/level of schooling/locality.
} 
Another important issue which emerged in our discussions with the young people was the distance they had to travel to reach school. Joyce noted that the absence of a school in the community was the reason she was not enrolled.

Because there was no school around that was why he did not enrol me as enrolling me in a faraway school, I would not be able to walk there (Joyce/F/PI/grade8/rural)

Kwaku (M/PI/grade12/urban) used to walk to school with a walking stick or crutches until he met a missionary who helped him to acquire a tricycle. He explained that as a result of his impairment he would arrive very late to school and added that he would sometimes even fall asleep in class due to fatigue.

Another mother noted that distance to school was one of the main causes for her son dropping out of school,

He actually was going to school but it was very sad to see how he suffered to get to school. At a point he stopped going. I tried to encourage him but he refused to say why he won't go. Since we also knew he suffered in getting to school, we allowed him to stay back (Mawusi/F/SO/rural)

In contrast, even though Ebo (M/PI/grade5/rural) acknowledged the difficulty he had in getting to school, described how he had been encouraged by his father to attend school. He painstakingly described how he used to crawl to get there, demonstrating incredible determination and the importance placed on education. This perception about the significance of education is elaborated upon later in the paper.

While the factors supporting or inhibiting school participation were not always disability specific, the kind of school setting that the young people attended differed considerably. While several of the participants did not attend formal schooling, some families enrolled their children in Makarantas, Islamic schools, valuing religious education over formal schooling.

[I: Why was he not sent to school?] I think it is because our people (Dagombas) prefer

Koranic school more than formal education, especially in rural areas (Amir/M/SO/rural)

However, it is not clear if this preference was only in relation to children with disabilities, as noted to be the case in Pakistan, where Singal, Bhatti \& Malik (2011) found that amongst parents of children with disabilities there was a clear preference for sending young boys with visual impairments for Qur'anic education. In our study in Ghana it remained unclear if the value placed on religious education was similar irrespective of gender and ability groupings.

\section{Experiences in school}

In describing their experiences in mainstream settings, young people tended to be very negative in their reflections and recalled hours of sitting idle in the classroom, unable to understand what was being taught and the absence of appropriate teaching and learning materials. 
We didn't have access to text books because we didn't have them in Braille. I'm talking about secondary school, we didn't have access to the library so we depended solely on our notes (Manu/M/VI/grade 12+/urban).

Kaseem shared similar experiences and noted his dependency on non-disabled peers.

We had no storybooks. We had nothing, textbooks, no. Only the sighted people used it. To get part of it, you needed to get somebody to read it to you and because of its large nature, they couldn't read everything to you. That is a very big problem for us and it is still facing us (M/VI/grade12/urban).

Although there was a noted lack of institutional support, eight participants commented on the informal assistance given by both PWDs and non-disabled peers when they encountered difficulties. For example, Esther (F/HI/grade7/urban) said she learned from her friends when she had difficulty understanding things, particularly when the teachers were unable to sign correctly because they were not trained. Addae said he never had a special teacher to help him, so he depended a lot on his school mates for support, which was readily given (M/HI\&PI/grade7/rural).

In interviews with the school heads, many commented that special schools seemed most suited for CWDs because, 'they will not suffer stigmatization and will need extra time in school. Learning is slow for many of them and they need special attention' (Ato/M/school head/rural).

Another school head reflected:

The biggest problem is with facilities. If teachers and facilities are provided it may work. Teachers need to be educated on issues of disability and to include it in teachers training programmes so that teachers from any training college can be posted to teach in a special school (Beeke/F/school head/urban).

\section{Perceived benefits of education}

Irrespective of their own educational status, as noted previously, across the sample participants placed immense importance on schooling. Young people discussed how important it was to be literate; being able to read and write, to speak in English, get a job and be included in the decision making processes within their family.

Education is very important and beneficial. At least after school, one can get a paid job. As I said, even in my state, I could have been employed, but I can't read. I can't write. Even to read time, I can't (Kaseem/M/PI/no schooling/rural).

Participants viewed education as a route to having a better life and gaining respect from the public and community. Kwaku articulated that school has helped 'a lot because I have identified my personality and how to live in society and command respect' (M/PI/grade12+/urban).

A female participant reflected on the following: 
The benefits I got cannot be measured. It isn't one thing we refer to as a benefit. It is not a job per se for me, but education carries a lot of things. When you are educated and you don't even get an official job to do, you and the uneducated astuteness can never be the same. (Joyce/F/PI/grade7+/rural).

A mother of a visually impaired man reflected on the impact of her son's education both on him and herself,

Schooling has actually helped him, otherwise I would have still been in poor because I wouldn't have been able to take care of him and he does not consider himself poor, let alone come out to beg. They (other PWDs) are on the streets begging but he said he didn't want (to do the same). He feeds from his pocket. Even if one sees him and gives him alms he won't accept it. It is the benefits of schooling that he is enjoying, and that is why he is not a beggar (Gifty/F/SO/urban)

Additionally, a few participants noted that they learned about their rights as a person with a disability and gained important insights.

As part of my course we studied the Disability Act so I realized that certain things used to happen, it was due to my ignorance about my rights, then that was why they were being abused (Manu/M/VI/grade12+/urban).

However, Tano reflected on his difficulty of exercising these rights,

You know this is your right and if you want to exercise it, some people try to shut you down but you have to be patient and courageous to challenge them... If not, they think that as you've become blind, all your rights are finished. So you need to tell them! They will initially not take it but gradually will come to accept it (M/VI/grade12+/urban)

Some of the participants, both youth and their significant others, also emphasised the social benefits to being educated.

I also learned how to relate to other people...I've become more friendly and patient (Manu/M/VI/grade12+/urban)

She thinks and behaves better. Knows what is right or wrong, learnt sign language and can now interact much better and a lot more with other deaf people (Jennifer/F/SO/rural).

\section{Realised outcomes of schooling: employment and community participation}

As noted earlier, all participants regardless of their educational status viewed schooling as paramount in improving their circumstances. Specifically, many identified education as a means with which to acquire the skills necessary for employment.

If I had not been to school I wouldn't have been able to do it. It would even be as a result of my schooling that I can do these jobs. Those who are not educated are begging on the streets. So schooling has helped me a lot (Joyce/F/PI/grade7+/rural). 
Ten of the young people in our sample group were either not working or engaged in begging. While years of schooling was not linked to a greater possibility of being employed (given that even those who had completed accountancy course were unemployed). It is interesting to note, that all the women participants who had not been to school were engaged in begging. For these individuals, begging was seen as the easier and only option available.

Blind people who are educated, do not come out (on the streets). Some of them are teachers and others are working...And life is good for them. But because we're not educated that is why we come out to go round and beg. Schooling is actually good (Adika/F/VI/no schooling/urban).

This particular double disadvantage faced by participants on account of their disability and gender has also been noted by Naami et al., (2012). Findings of their study in Tamale (Ghana) highlighted that even though women with disabilities want to work, various institutional, physical, and attitudinal barriers prevent them from becoming gainfully employed, as a result the majority of them have to live a life of dependency on their family and friends, while others engage in menial jobs and begging for survival. Participants in their study identified inadequate education as one of the factors in their exclusion from work opportunities, which is also highlighted in the findings of our study.

Young people who had not received any formal education were very pessimistic about their employment prospects and also tended to exhibit very low levels of social engagement with other members of the wider community,

Apart from teaching in the Koranic school, I have not learnt any skills. I also help with jobs in the house but none is a skilful job. This is why I am under these trees most of the time (Donkor/M/HI/no school/rural).

These feelings were in most cases also shared by their significant others.

He likes to work but since he did not go to school and has no special or vocation or even technical skills, he is forced to just hang around (Coffie/M/SO/rural).

Individuals who had achieved higher levels of schooling but were seeking employment noted the difficulties encountered when looking for work and tended to be more critical of existing social structures. Kwaku (M/PI/grade12+/urban) reflecting on his experiences noted that when people think about employing people with disabilities they see it as doing them a favour rather than the PWDs right as citizens, even if the person has all the requisite qualifications. An observation which has been shared by others (MoESW, 2000) as noted earlier in the paper.

Additionally, participants with higher levels of schooling years were also considerably more active in their community through sports and other associations. Nana (M/PI/grade12+/urban) acted as a resource person for other people with disabilities in his community. For example, he advised people with visual impairments to enrol their children in school, instead of instructing them to go to the streets to beg. Few others noted the following: 
I take tea and dress up, come out to meet friends and we will discuss politics. I also go to school. During the weekends, I have blind sports and I am the president (Sono/M/VI/grade12+/urban).

...I sit to reflect upon my report writings because I am the leader of our association. So when I wake up, I reflect on developing new ideas so that when we sit for meetings, I discuss it with the others (Manu/M/VI/grade12+/urban).

Notably, all participants in our sample group who were actively engaged in their communities whether through formal and informal associations were male, educated above secondary level and lived in urban settings.

\section{Conclusion}

The research participants in our study noted a range of barriers in accessing education, contributing to their communities, and gaining employment. Even though a few gender differences were evident, broad commonalities existed in the lives of these young people, which were largely marked by difficulties in participation and accessing their rights. While education is acknowledged as being essential to gaining employment, as noted in policy documents and personal narratives, many young people remain excluded from education. The young people and their families noted a range of factors which limited their meaningful engagement in schooling. Findings from our study suggest that while parents of children with disabilities were not opposed to their child's schooling and recognised its many benefits; in many cases they were unable to enrol their child due to various factors, such as costs and distance.

Even though recent years have seen a growing focus on education of children with disabilities, our analysis of the census data demonstrates that the percentage of children with disabilities amongst the out of school population has actually increased in comparison to those without disabilities. While acknowledging that reporting of data is hugely problematic these insights also raise concerns that current efforts may not be reaching the hardest to reach, who are also the most in need. Results from our interviews also highlight that the increased government focus has not adequately addressed the additional (and real) barriers facing students with disabilities such as associated schooling costs, lack of adequate transportation, unavailability of curriculum support and the absence of trained teachers. All these factors were raised at various points by both the young people and their parents, and even heads of schools. These concerns are similar to those voiced by mainstream teachers in the study by Ocloo \& Subbey, 2008) who felt inadequately trained and supported to respond to the needs of children with disabilities. The researchers based on their findings also noted, "...that the Ghana Education Service and other stakeholders of education pay mere lip service to the provision of services to inclusive school environments" (p. 639).

Parents and young people, irrespective of their schooling levels, emphasised the many benefits of education. The promise of a better life as a result of being educated emerged strongly in their narratives, even though evidence of this was not necessarily found in their current reality. These findings are not specific to Ghana. For example, Singal et al (2012) 
noted similar experiences amongst youth with disability in the South Asian context. In their research with young people in urban and rural settings in India they noted that people with disabilities and their parents placed a lot of value on schooling, not only in terms of gaining employable skills, but also in terms of gaining respect and dignity of community members and in assisting people with disabilities to develop basic skills which would allow them to function independently. Within the Ghanaian context these perceptions, especially in relation to employment were also voiced by the young people, however being better educated did not result in better jobs. However, the complete absence of schooling was seemingly related to the greater likelihood of the person ending up begging and also living on the margins of community life. Many of these reflections are also shared in their research by Botts and Owusu (2013).

Young men in our sample who did achieve high levels of schooling noted benefits such as increased awareness of their rights, and greater community participation, nonetheless they remained very conscious of the significant challenges they faced in gaining employment and in changing the negative perceptions of those around them. Thus, indicating that even though over the last few years, the government has demonstrated a commitment to change by proposing various policy initiatives, such as the passing of the PWD Act and a commitment to their education through various ESP directives, much more remains to be done. At one level, frustrations expressed by the young people in our study were no different from their non-disabled peers, as poverty and unemployment remains a significant challenge for Ghana. Abbink (2005) noted that, 'to be young in Africa (has come) to mean being disadvantaged, vulnerable and marginal in the political and economic sense' (p. 7). However, our findings highlight that being disabled further accentuates experiences of vulnerability and reinforces the marginal status of this group. Education has a central role to play in shaping the lives of people with disabilities, but it is unlikely to deliver promises of a better life on its own; systematic changes in the policy arena are needed to enable youth with disabilities to take their rightful place in mainstream society. At the level of schooling there is a need to develop programmes which support teachers with adequate training to respond to the diverse needs of children in their classroom. Additionally, there is a need to offer prospective employers positive incentives to employee people with disabilities. Fundamentally, more needs to be done in recognising the potential of people with disabilities and providing them with opportunities to make a positive contribution to society. 
Abbink, J. 2005. Being young in Africa: the politics of despair and renewal. Retrieved from: https://openaccess.leidenuniv.nl/bitstream/handle/1887/9608/ASC_1242160_167.pdf? sequence=1 Accessed on 07 May 2014.

Adera, B., \& Asimeng-Boahene, L. 2011. The perils and promises of inclusive education in Ghana. Journal of International Association of Special Education, 12(1).

Agbenyega, J. \& Deku, P. 2011. Building new identities in teacher preparation for inclusive education in Ghana. Current Issues in Education, 14(1), 1-36.

Agyemang, C. B., \& Delle, E. 2013. Demographic factors and attitude toward disabled employees: empirical evidence from Ghana. Research on Humanities and Social Sciences, 3(19), 53-59.

Anthony, J. H. 2010. Access to education for students with autism in Ghana: Implications for EFA. Background paper prepared for the Education for All Global Monitoring Report.

Appiagyei-Atua, K. 2006. A New Disability Law in Ghana: The Way Forward. A paper presented at the second Annual CHRAJ-GBA-CHRI Lectures, 2006, Accra. As cited in UNDP (2007). Ghana Human Development Report: Towards a More Inclusive Society. Accra, Ghana: UNDP.

Avoke, M. 2001. Some historical perspectives in the development of special education in Ghana. European Journal of Special Needs Education, 16(1), 29-40.

Baffoe, M. 2013. Stigma, discrimination \& marginalization: Gateways to oppression of persons with disabilities in Ghana, West Africa. Journal of Educational and Social Research, 3(1), 187-198.

Botts, B. H., \& Owusu, N. A. 2013. The State of Inclusive Education in Ghana, West Africa. Preventing School Failure: Alternative Education for Children and Youth, 57(3), 135-143.

Department for International Development (DFID). 2000. Disability, poverty and development. London: DFID.

DESA (UN Department of Economic and Social Affairs). 2011. Disability and the Millennium Development Goals: A Review of the MDG Process and Strategies for Inclusion of Disability Issues in Millennium Development Goal Efforts, New York: UN.

GES (Ghana Education Service). 2005. Special Educational Needs policy framework: Special education division. Accra: Republic of Ghana .

Ghana Statistical Service (GSS). 2012. 2010 Population and Housing Census: Summary Report of Final Results. Accra: GSS.

GSS. 2013. 2010 Population and Housing Census: Demographic, Social Economic, \& Housing Characteristics. Accra: GSS. 
Groce, N. 2011. Disability and the Millennium Development Goals: A Review of the MDG Process and Strategies of Inclusion of Disability Issues in Millennium Development Goal Efforts. New York, USA: UN.

Hashim, I.M. 2005. Exploring the Linkages between Children's Independent Migration and Education: Evidence from Ghana. Working Paper T-12. Brighton: Sussex Centre for Migration Research.

ILO (International Labour Organization). 2014. Global Employment Trends 2014: Risk of a Jobless Recovery? Geneva: ILO .

Institute for Statistical, Social and Economic Research (ISSER). 2010. The State of the Ghanaian Economy in 2009. Legon, Ghana: University of Ghana.

Kuyini, A. \& Abosi, O. 2011. The 2nd Generation Street Children (SGSC) in Accra: Developing Teaching Strategies to Enhance Positive Learning Outcomes in Schools. World Journal of Education, 1 (2).

MoE (Ministry of Education). 2003. Education Strategic Plan 2003-2015: Volume 1 Policies, Targets and Strategies. Accra: MoE .

MoE. 2012. Education Strategic Plan 2010-2020: Volume 2 - Strategies and Work Programme. Accra: MoE.

MoE. 2013. Education Sector Performance Report. Accra: MoE.

MoESS (Ministry of Education, Science \& Sports). 2008, Preliminary Education Sector Performance Report. Accra, Ghana: MoESS.

MoESW (Ministry of Employment and Social Welfare). 2000. National Disability Policy Document. Accra: Republic of Ghana.

MoESW. 2012. National Employment Policy 2012-2016. Accra: Republic of Ghana.

Mont, D. 2007. Measuring Disability Prevalence, Social Protection Discussion Paper Series, The World Bank, No. 0706, 1-42.

Morley, L., Leach, F, Lussier, K., Lihamba, A., Mwaipopo, R., Forde, L. \& Egbenya, G. 2010. Widening Participation in Higher Education in Ghana and Tanzania: Developing an Equity Scorecard. Brighton, UK: University of Sussex.

Naami, A., Hayashi, R. \& Liese, H 2012. The unemployment of women with physical disabilities in Ghana: issues and recommendations, Disability \& Society, 27 (2) 191-204.

Nketsia, W., \& Saloviita, T. 2013. Pre-service teachers' views on inclusive education in Ghana. Journal of Education for Teaching, 39(4), 429-441.

Neuman, W. L. (2000). Social research methods: Qualitative and quantitative approaches. London: Allyn and Bacon.

Ocloo, M. A. \& Subbey, M. 2008. Perception of basic education school teachers towards inclusive education in the Hohoe District of Ghana. International Journal of Inclusive Education, 12 (5-6), 639-65. 
Republic of Ghana (RoG). 1961. National Education Act (Act 87). Accra: RoG .

Rose, P. 2012. Africa: 'Education First' and the Disadvantaged First and Foremost. Opinion piece. http://allafrica.com/stories/201209270227.html

RoG. 1992. Constitution of the Republic of Ghana. Accra: RoG.

RoG. 1998. Children's Act (Act 560). Accra: RoG.

RoG. 2006. Persons with Disability Act (Act 715). Accra: RoG

Singal, N., Bhatti, F., \& Malik, R. 2011.Counting the invisible: understanding the lives of young people with disabilities in Pakistan, Disability \& Rehabilitation, 33 (11), 908921.

Singal, N., Bhatti, F., Janjua, S \& Sood, N. 2012. Outcomes for young people with disabilities: increased expectations but unrealised gains in South Asia. In C. Colclough (eds) Education outcomes and poverty: a reassessment. Oxon: Routledge.

UNDP. 2007. Ghana Human Development Report: Towards a More Inclusive Society. United Nations Development Programme: Ghana Office.

UNESCO Institute of Statistics. N.D. UIS Statistics in Brief: Education (all levels) profile Ghana. Retrieved from http://stats.uis.unesco.org/unesco/TableViewer/document.aspx?ReportId=289\&IF_La nguage $=$ eng\&BR_Country $=2880 \& B R \_$Region=40540 accessed on 27 February 2014

UNESCO. 2014. Education For All Global Monitoring Report 2013/2014. Paris: UNESCO.

UNICEF. 2012. Global Initiative on Out-of-School Children: Ghana Country Study. Accra: UNICEF.

UNICEF. 2013. Children and Young People with Disabilities: Fact Sheet. New York,: UNICEF.

WHO. 2011. World Report on Disability. Geneva: WHO. 